\title{
Racism in Health Services in Brazil
}

\section{Cristina Gomes}

Facultad Latinoamericana de Ciencias Sociales, FLACSO, Sede, México

Email: cristinagomesmx@gmail.com

How to cite this paper: Gomes, C. (2016). Racism in Health Services in Brazil. Advances in Applied Sociology, 6, 363-374. http://dx.doi.org/10.4236/aasoci.2016.611027

Received: September 3, 2016

Accepted: October 29, 2016

Published: November 1, 2016

Copyright $\odot 2016$ by author and Scientific Research Publishing Inc. This work is licensed under the Creative Commons Attribution International License (CC BY 4.0).

http://creativecommons.org/licenses/by/4.0/

(c) (i) Open Access

\begin{abstract}
This article discusses racial prejudices and discrimination in perceptions, attitudes and practices among health personnel in the municipality of Camaçari. The survey's methodology included racist statements in questionnaires distributed to 634 health workers, as well as socio-determinants of health, family and work characteristics. Results indicate how masked racism is reproduced through ambiguous attitudes and practices; the feeling that speaking about race/color would create a racist conflict, supposing that it does not exist, and resistance against accepting the need to correct injustices and promoting affirmative policies.
\end{abstract}

\section{Keywords}

Racism, Racial Inequalities, Racial Discrimination, Health Personnel, Health Services

\section{Introduction}

With the return of democracy, Brazil has implemented various social policies covering more than 30 million people with income transference (BolsaFamilia), the reduction of poverty and elimination of hunger, the creation of more than 2 million units of affordable housing and providing more than 2 million people over 65 or people disabled with a minimum wage income. Despite these efforts, there are still families and people with health problems and vulnerabilities, such as violence, drug abuse, disability, natural disasters and victims of discrimination. One of the barriers to full citizen inclusion is the racial disparity that has characterized Brazilian society, institutions and microrelationships throughout its 516 years of history.

Until beginning the 20th Century, the Brazilian population was predominantly black (slave or descendant of the enslaved ${ }^{1}$ ) (Klein, H.S.; III, Ben Vinson, 2007), illiterate and defined in newspapers and by Brazilian intellectuals as "bestializada" (made beasts), a reason for national shame (Carvalho, 2004).

${ }^{1}$ Brazil was the last independent country in the world to abolishing slavery, in 1888. 
Racism has become an intrinsic part of the formation and development of Brazilian society, and has been reproduced in the present day through a false myth of "racial democracy" and the ideal of the "whitening" of society (Fernandes, 1965; Bento, 2002). A sui generis racism, masked and widespread, persists in all power structures and national, state, municipal institutions, and micro social, both individual and familial (Guimarães, 1999; Alencar, 2013; Amaral, 2011; Brasil, 2013; Brasil, 2016).

As a result, blacks in Brazil have the worst rates of morbidity, mortality, and illiteracy, and have lower educational levels and higher poverty rates within the population (Brasil, 2013). There are incidents of racism witnessed on a daily basis in the media, social networks, public spaces and institutions and even among members of the same family, but prejudices and discriminatory attitudes are denied and hidden, masked by a belief that in Brazil there is a peaceful miscegenation process and an alleged racial democracy (Brasil, 2013; Brasil 2016; Alencar, 2013; Amaral, 2011).

According to Santos (2007), "prejudice plays its daily aggression against black people alternating silences, whispers, speeches and shouts." The first two forms are the most used, because they allow racism to hide whilst acting to keep the facade of people as "morally intact, mentally healthy" ("good"), which would have "authority" to discriminate and have power over the "other", since blacks are considered to be in an inferior social position.

It is a very common and socially acceptable treatment to transmit the idea of "knowing your place"- that is, an inferior place for blacks. The referred inferior place means that "there are others who deserve more than you, there are others who have priority, you are less important". Even subconsciously, silence, looks, and attitudes can portray to black people this message of their supposed inferiority, something Brazilians learn from childhood (Brasil, 2007).

These daily witnessed incidents of racism are present in the media, social networks, public spaces and institutions and even among members of the same family. And the general opinion is that it happens by mainly denying and hiding prejudices and discriminatory attitudes, masking them in jokes, comments, views and suspicious attitudes, often without being aware of them, these characteristics having been learned from an early age.

Besides this subtle and unconscious type of racial discrimination, there is also "the practice of prejudice such as irony, sarcasm and exasperation, the jokes and the nervous smile, when, for a few seconds, we realized that we would be contradictory or racist" (Ribeiro, 2012).

In Brazil, the "negro" population is composed of people who define themselves as black or mulatto/brown. In 2013, these groups represented 52.9\% of the population, around one hundred million people. In the public health system (SUS), 70\% of users are self-defined as black (black and brown). Brazil is the country with the second largest number of black people the first is Nigeria and Bahia is the State with the highest proportion of black inhabitants, as is the Metropolitan Region of Salvador, the capital, in which Camacari is included (Brasil, 2016). 
The classification of "color or race" used in censuses and surveys is obtained using induced self-definition, i.e. the respondent is free to indicate their "color or race" between the five categories (black, white, brown, Asiatic, indigenous) which are already well accepted as virtually the entire population responds to censuses and surveys and is able to define their color themselves (Osório, 2003).

Civil servants of the federal agencies have more difficulties when asked about race or color. Only $40 \%$ of the 584,000 active employees completed the question of "color or race" in their record of personal data in 2003; in some institutions only $3 \%$ of employees responded to this question (Osório, 2003). Therefore, it is expected that public employees have a greater tendency to deny the existence of racism, and to whiten their skin color and the color of service users.

Available data on color/race show that the black population (both black and brown) in Brazil has the highest rates of morbidity and mortality, the highest illiteracy rates and the lowest educational levels, the highest rates of poverty, infant and maternal mortality, mortality from diabetes, hypertension and violent deaths, and accumulate all these social disadvantages, as compared to the white population. Diseases are more prevalent in the black population; sickle cell disease, hypertensive disorders of pregnancy, arterial hypertension, and diabetes mellitus amongst others (Brasil, 2016; Batista et al., 2013; Dias et al., 2009; Araújo et al., 2010; Goes \& Nascimento, 2013).

In the last two decades, Brazil has adopted actions to compensate and correct race inequalities and discrimination. Affirmative or positive policies are special and temporary measures imposed to support those who are black, disabled and those who are the poorest-the most in need of assistance to achieve equality. These policies would be temporary and work for a limited period, until the attainment of equal opportunities for all (Silva Filho, 2008).

Despite all these efforts to increase income, to equalize access to services and to diminish inequalities and disadvantages of the most vulnerable groups, it is very common in Brazil in the communications media that some population groups criticize social measures, arguing that all have the same opportunities, and that results are based upon individual merit. Controversies and conflicts in society raise the argument that race inequality is an imported issue that could create or promote a problem that "does not exist" in Brazilian society. Another reason for conflicts is the interpretation that the inclusion of blacks with affirmative policies could generate discrimination against white people.

In order to understand how these policies would work in health services, this article has the objective of analyzing statements of prejudices in perceptions, attitudes and practices of workers at health services in Camaçari, Brazil, and to discuss correlations and principal components of these prejudicial statements, classified in grades from clear to masked racism. Considering the Brazilian academic consensus on the myth of racial democracy as the main characteristic of racism in Brazil, some categories were built into a scale: explicit racism, no-adherence to affirmative measures and racism denegation (based upon the denial of racial inequalities). 


\section{Methodology}

A representative survey was distributed to 634 workers of the public and private health services, with a questionnaire concerning socio-demographic characteristics, family, work conditions and perceptions, and attitudes and practices in racial relationships. The vast majority of the workers are women $(76 \%)$ and their mean age is 40 years old; $83 \%$ declare they are Negros ( $31 \%$ black and $52.2 \%$ brown or mixed race) and only $14 \%$ are white; $42 \%$ are Catholics, $21 \%$ Evangelical, $17 \%$ have no religion, $15 \%$ are spiritualists or have Afro-religions. Half of them are married, 38\% single, $9 \%$ separated, $2 \%$ widowers and $2 \%$ live in other marital status. The majority have children (63\%): $33 \%$ have one child and $23 \%$ have 2 or more children. Most of them (69\%) are head of their households, the average size of households is 2.9 members, and they earn on average a salary of three thousand of Reais per month (approximately one thousand US dollars), and $70 \%$ have a formal labor relationship as public workers.

Variables were created by adopting statements about race relationships obtained from personnel of health service in different cities of the country. These statements were accessed by previous authors using qualitative methods and published in scientific articles (Santos \& Santos, 2013; Tavares et al., 2013; Grandi et al., 2013). These statements are listed in the questionnaire, applied to personnel working in different functions, from the front-of-house security and reception personnel to community agents, technical personnel, nurses, physicians and the health service managers. Some examples of these statements are:

a) If you ask about race or color, what is or would be the reaction of the users?

Naturalness, Surprise, Distrusting, Questioning/do not understand, Uncomfortable, Refusal to answer, Irritation, Refusal to take his race: I see they are black, they say white.

b) How would you feel to ask the race-color to users?

Normal, it is no big deal, Uncomfortable, Constrained, Feel you are discriminating patients, Fear of offending the patient, Fear of being questioned, Fear of being misunderstood, It's unnecessary, It delays the service.

c) There is racism in Brazil? (level)

d) Have you experienced or observed of racism?

e) What is your opinion on the following statements: (totally agree, partially agree, disagree).

- It is not necessary to differentiate people by skin color in health services. The country is inter-bred it has no way to frame the person in a single race.

- It is important to fill this item to know the profile of people who have diseases associated with race/color, support the treatment and identify prejudices.

- It's hard to ask the patient what his color. We created unnecessary controversy, as there are different races in Brazil and people are in doubt about that.

- It's embarrassing to ask color, people may take offense, create problems. They do not want to answer.

- Needless to ask the user color. The community is not used. 
- It should not be asked the user color. It is not necessary. That's not part of my job.

- It is natural to consider the color-race of the population, as the age or sex. I cannot take a white or black person, a teenager or a senior citizen, a man or woman in the same way.

- The black population has the worst rates of illness and death, so we have to have a focused look at the color, differentiate the service to reduce inequalities.

- Recognize the specific health problems of the black population do not imply prejudice or discrimination against whites.

- To have true equality we have to recognize racial differences and treat them differently, so we fight against racial inequality.

- Differential treatment by color or race is a type of discrimination it is racism, because everyone is equal according to law.

- Racial quotas discriminate against whites, it's not fair, because we have to meet all the same all have the same rights.

- Jokes about blacks and the use of the term "bad hair" or "the situation is black" are part of the culture of the population, are not racist expressions.

- Blacks tend to be more aggressive than whites.

- Brazilian law defines the crimes of racism, discrimination or race-color prejudice like refusing access in public places, with imprisonment from 1 to 3 years as punishment.

Proportions and correlations between socio-demographic variables and discrimination statements, such as Pearson coefficients were estimated.

Principal Component Analysis was used when a large number of categorical variables would be classified and grouped, as in this study, to reduce the number of variables to a few, interpretable linear combinations of the data. Each linear combination corresponds to a principal component (PCA). The First Principal Component is the linear combination of $\mathrm{x}$-variables that has maximum variance (among all linear combinations), so it accounts for as much variation in the data as possible. The Second Principal Component is the linear combination of $\mathrm{x}$-variables that accounts for as much of the remaining variation as possible, with the constraint that the correlation between the first and second component is 0 (zero). All subsequent principal components have this same property-they are linear combinations that account for as much of the remaining variation as possible and they are not correlated with the other principal components. To interpret each component, we must compute the correlations between the original data for each variable and each principal component. Because of standardization, all principal components will have a mean of 0 (zero). The standard deviation is also given for each of the components and these will be the square root of the eigenvalue. More important for our current purposes are the correlations between the principal components and the original variables.

Principal Component Analysis is applied for each personnel group, according to different levels of education and for the entire population. The statistical program used was SPSS version 22 . 


\section{Results and Discussion}

Descriptive data shows that nearly $60 \%$ of the health personnel with the highest levels of education expect that patients will naturally answer their race/color, and that it is important to include this question in health registers, to know the disease profile of the black population in order to support treatment and to identify prejudices. However, less than half of personnel in the lowest levels of education (fundamental, with 8 years of education, such as receptionists) agree with this statement.

Only $40 \%$ of the personnel have positive expectations about the reaction of patients when asked about their color. Negative expectations and personnel's fears about patients reactions are more common among personnel with low level education; around $30 \%$ of them expect that patients would feel bothered by or would not understand the question, or do not accept their own color, or feel embarrassed, that this question would create unnecessary controversy, that people are in doubt about their color/race, or that they may take offense, feel bad, create problems, or even that they don't want to answer about their color. These would be interpretations of some health personnel who are transferring their own prejudices or feelings of superiority regarding patients.

Half of them resent asking the color of patients, using different excuses such as; it is not necessary, it is not part of their job; the community is not used to this; and they do not consider asking color as natural as asking sex or age. Almost all these ambiguous answers against asking the color of patients have higher proportions among personnel with lower levels of education, compared to doctors and other professionals with a university degree, who are more accepting of the existence of racial inequalities and its relevance to the development of health policies and actions.

However, to accept the existence of inequalities does not imply accepting policies to reduce it with affirmative policies. On the contrary, $46.8 \%$ of the personnel are against racial quotas, and $61.6 \%$ consider that giving special treatment to reduce inequalities would discriminate against whites, and be reverse racism. Again, these resistances to accept actions to reduce inequalities are higher amongst less educated personnel, who are $65.6 \%$ against quotas and $78.9 \%$ against giving special treatment to black people in health services.

This resistance against recognizing the need to correct inequalities with special policies is also in contrast to $80 \%$ of personnel who agree that racism exists and is very common, whilst only four people (out of 364 surveyed) directly assume that racism does not exist in the country.

This contradiction could be interpreted as, in spite of almost everybody recognizing that racism exists, that the wide majority believes in racial democracy, and ambiguously believes that there is no need to differentiate people by skin color in health care, because the country would be interbred, and that "it is not possible to fit a person into a single race category". As inequalities are accepted as "natural", special actions to reduce it are considered "unnecessary". Some qualitative statements in this research are "it has always been so", and "it's not my problem, but a problem of my predecessors". 


\section{Principal Components Analysis}

The interpretation of the principal components analysis is based upon which variables are most strongly correlated with each component. From a large number of variables, the farthest from zero in either positive or negative direction are more correlated. In this case a correlation value above 0.55 was established.

For the entire population, the first principal component (PCA1) is strongly correlated with five of the original variables. The first principal component increases with the following statements scores: Recognition of black problems whilst not meaning discrimination against whites; humanizing SUS is enough to prevent racism; asking patients color is unnecessary and it is not my job; differences exist and race inequalities are relevant; it is hard to ask color/race and it generates unnecessary controversy; it is not necessary to ask color/race as the country is interbred; it is unnecessary and the community is not used to such a question. This suggests that these criteria vary together. If one of them increases, then the remaining ones tend to increase as well. This component can be viewed as a measure of typical masked and defensive sentences representing the myth of racial democracy. For example, the belief that differences exist, that race inequalities should be known and are relevant. However, these statements are immediately followed with many conditions or pretexts to immediately deny any affirmative attitudes to correct them and to promote equality (Table 1).

The second principal component (PCA2) increases with only three types of expectancies on patient's negative reactions when asked about their race/color, justified by different reasons; people may question, misunderstand, take offense, and create problems and controversies. However, these expected conflicts, according to the myth of racial democracy, wouldn't exist in Brazilian society. So, again, prejudices are transferred to "the other". This component can be viewed as a measure of how important it is to deconstruct these expectations in training courses for health providers.

In the third principal component (PCA3) any variable achieves the level established as a coefficient higher than 0.55 . The highest coefficient (0.503) corresponds to the expectation that patients would deny their own race, and say they are white but the interviewer believes they are black.

Explicit demonstrations of racism are only included at PCA 4: Does racism exist in Brazil? However, the coefficient is lower than the established level (0.469). At PCA5 the statement "black people are more aggressive than whites" has the second highest coefficient (0.605). Therefore, explicit racism is uncorrelated to all the other variables in previous group. These are isolated cases.

Considering that different patterns of discriminatory statements are shown according to the positions assumed by health personnel, the Principal Component Analysis is estimated to consist of four groups: doctors, other professionals with a university degree, technical staff and non technical staff.

The First Principal Component (PCA1) for doctors includes several correlated variables. This is the unique case in which PCA1 includes explicit racist statements: "Jokes on blacks is Brazilian culture, is not racism" and "Blacks are more aggressive than 
Table 1. Principal components for different groups of personnel in health services, Camacari, Bahia.

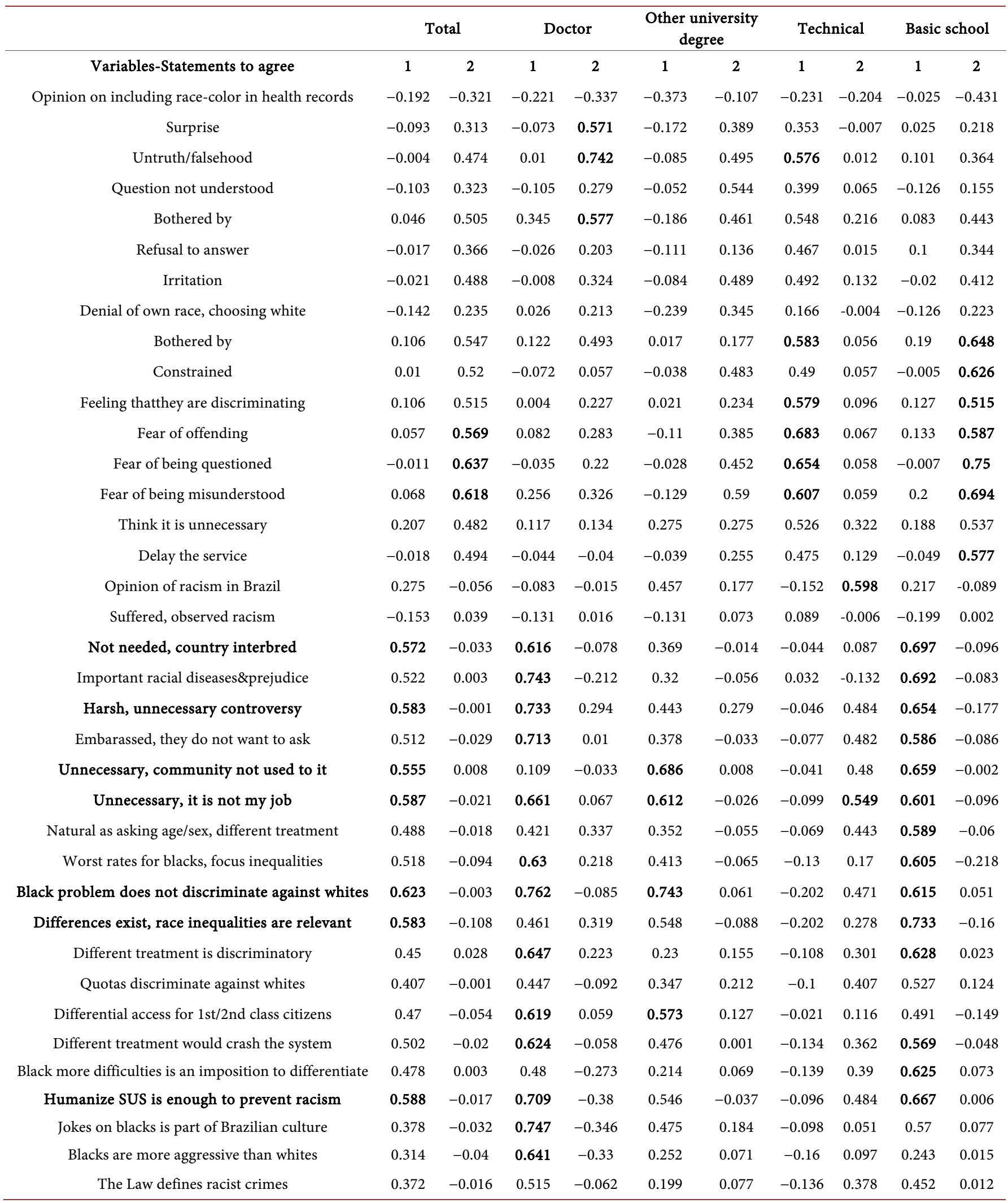


whites". These harsh statements are as strongly correlated as the recognition of the importance and relevance of racial differences in health. Doctors combine explicit racism and ambiguity concerning the myth of racial democracy and excuses about "other" feelings; it's hard to ask because it cause unnecessary controversy; it is embarrassing because they do not want not to answer, it is not necessary because the country is interbred, and black problems do not discriminate against whites. Other statements recognizing racial differences are also correlated in doctor's opinions, such as the recognition that there exists differential access for citizens of first and second classes. The second component (PCA2) for doctors includes only negative expectations from patients when asked about their color: surprise and falsehoods.

The group of other personnel with university degrees includes a low discrimination profile and ambiguities in their statements. Their first component (PCA1) includes only utilitarian statements like how questioning patient color is unnecessary because the community not used to this question, it is not my job, and the program Humanize SUS is not enough to reduce racial differences. They also recognize that black problems do not discriminate against whites. It is important to note that, in opposition to doctors, this group is mainly composed of young black women. Most of them probably benefited from affirmative policies, such as racial quotas, enabling them to enter to university and public employment. In qualitative interviews at least three of them relate they have suffered racial discrimination from patients. One dentist relates that patients prefer to be treated by the other colleague who is white, and they refuse to be treated by her, just because of her color. A nursery attendant says that patients ask her to correct and verify medications and procedures recommended by a black nurse, who is her boss; but patients do not trust her opinion, despite her university degree, just because she is black. Another nurse experiences racism daily at work, since patients never answer her public "good morning", as they answer her colleague, who is white.

Technical personnel refer to few statements in their first principal component, mainly their own expectations about a patient's reaction when asking their color, such as they feel bothered, discriminated against, offended, questioned, or misunderstood.

Personnel with the lowest level of education are mainly receptionists, security staff, ambulance drivers, telephone operators, etc. The PCA1 of this group is the largest group of discriminatory statements, including: it is important to know racial inequalities in diseases; it is as natural to ask color, just as asking age and sex; blacks have the worst rates in health; focusing upon black problems does not discriminate against whites; race inequalities are relevant. These positive statements recognizing inequalities are also correlated to other ambiguous statements that reaffirm the myth of racial democracy, such as: it is not necessary to ask color because the country is interbred; it causes unnecessary controversy; it is embarrassing because they do not want to answer; the community is not used to it. However, this group also has pragmatic arguments like "it is not my job" and "different treatment for blacks would crash the system"; as well as resistance to accepting affirmative policies: different treatment for blacks means to discriminate against whites; and that is because blacks have more difficulties we would not 
accept this imposition to differentiate between health services access.

This suggests that recognition of race inequalities, ambiguous racism of the myth of racial democracy, supposed pragmatic arguments against correcting race injustices and to be clearly against inclusive policies are correlated, and vary together. If one increases, then the remaining ones tend to do so as well. This component can be viewed as a measure of typical masked and defensive sentences representing the myth of racial democracy, but also concluding that affirmative policies are unnecessary, or even "an imposition" which can discriminate against whites.

The PCA2 of this group also includes statements that transfer to patients a feeling of being bothered, constrained, discriminated, offended, questioned, misunderstood, when asked their color. PCA2 also includes warnings about delaying services to justify not asking the color of the patient.

The limits of this research include the tendency of respondents to answer in accordance with the expectations of the interviewers, opting for socially acceptable responses. To control partially this effect in the questionnaire including diverse types of responses. For example: according to previous studies, it was expected that almost all respondents assume that there is racism in Brazil. Therefore, in the following questions were included some common ambiguous statements related to racism, for example, the idea of reverse racism (offering affirmative policies for blacks may create discrimination against whites). Another limitation is that patients were not interviewed. It was necessary in this first approaching, to avoid the refusal of officials to answer the questionnaire in front of patients, and the embarrassment of the patient to give their opinion in front of the public servants. In participant observation it was found that indeed the majority of employees do not question the color of patients, what reconcile whit their own answers.

\section{Conclusions}

Brazilian academic papers put an emphasis upon the sui generis Brazilian racism, masked by ambiguity and based upon the myth of racial democracy. This ambiguity would be used to deny or to hide it beneath speech and respectable attitudes. The results of this research show that race discrimination is not so ambiguous; it is firstly introduced by a formal recognition of race inequalities, but immediately denied with excuses which transfer prejudices to black people.

In the case of doctors, ambiguous statements are also correlated to explicit racism. In another extreme, health personnel with a low level of education use much more ambiguous statements to justify race inequalities and injustices.

And the group of the younger, black females who recently were massively included at universities and as health personnel through inclusive policies such as racial quotas, uses much less ambiguity and pretexts to divert from common sense to deny racism and to escape from the responsibility of correcting injustices. However, they frequently suffer race discrimination from patients, and are perceived as less qualified personnel.

Explicit racism is evident in the case of patients refusing to be treated by black 
professionals, particularly by the group which less frequently reinforces ambiguous and explicit racist statements, compared to others.

Results lead one to think a term "revived ambiguity cycle", related to the feeling that speaking about race/color, would create a racist conflict, supposing firstly its non-existence. The mask of Brazilian racism is based upon the recognition of inequalities and injustices, but immediately followed by a resistance to asking about it, and refusing to correct it through affirmative policies. This circularity allows Brazilian society to use the egalitarian discourse, to accept inequalities as something that is unjust, but natural. Universal and egalitarian statements also deny any equalitarian action to correct injustices.

Results of quantitative study confirm how institutional racism is being reproduced in speech, attitudes and practices of the health personnel-from receptionists to nurses and physicians, in different levels and patterns. Racism is also present in patient attitudes and practices when they interact with black workers at health services, as demonstrated in our qualitative approach.

The results indicate a kind of "revived ambiguity cycle", related to the recognition that race inequalities exist and are unfair, but should never be talked about, in order to avoid racist conflict and white discrimination, and therefore society can continue to conjecture that it does not exist, and to use it to deny the need of affirmative policies and a commitment to reduce racial inequalities and to correct injustices.

\section{References}

Alencar, J. A. (2013) Stay Where You Belong: Review of Machado de Assis-Multiracial Identity and the Brazilian Novelist, by G. Reginald Daniel. Machado de Assis on line, v. 6, n. 11, pp. 134-139, June 2013. Rio de Janeiro: Foundation Casa de Rui Barbosa.

Amaral, S. P. (2011). The History of the Negro in Brazil. Training Course for the Teaching of History and Afro-Brazilian. Brasilia: Ministry of Education. Secretary of Continuing Education, Literacy and Diversity; Salvador: East Africa Studies Center.

Araújo, C. L. F., et al. (2010). The Question of Color/Race in Health Forms: The Vision of Health Professionals. Revista Enfermagem UERJ, 18, 241-246.

http://www.facenf.uerj.br/v18n2/v18n2a13.pdf

Batista, L. E., Monteiro, R. B., \& Medeiros, A. R. (2013). Racial and Health Inequities: The Cycle of Health Policy of the Black Population. Health Debate, Rio de Janeiro, 37, 571-579.

Bento, M. A. S. (2002) Bleaching and Whiteness in Brazil. In Social Psychology of RacismStudies of Whiteness and Whitening in Brazil. Iray Carone, Maria Aparecida Silva Bento (Organizing) Petrópolis, RJ: Vozes.

Brasil (2016). SEPPIR. Promoting Racial Equality. For a Brazil without Racism. 1st Edition. Brasilia, 2016. Special Secretariat for the Promotion of Racial Equality (SEPPIR). Ministry of Women, Racial Equality, Youth and Human Rights. Organizing Katia Regina da Costa Santos \& Edileuza Penha de Souza.

Brasil. Ministry of Health (2013). National Comprehensive Health of the Black Population Policy on Health Unique System (SUS) Policy (2nd ed.). Brasilia: Ministry of Health.

Carvalho, J. M. (2004). The Bestialized-Rio de Janeiro and the Republic It Was Not. São Paulo: Compania Das Letras. 
Dias, J., Giovanetti, M. R., \& Santos, N. J. S. (2009). Asking Offends: What Is Your Color or Race/ Ethnicity?: Answering Helps Prevention. In: Prevention of STD/AIDS. CRT-DST/AIDS.

Fernandes, F. (1965). The Integration of Black in Class Society. São Paulo: Dominus S.A

Goes, E. F., \& Nascimento, E. R. (2013). Black and White Women and Levels of Access to Preventive Health Services: An Analysis of Inequalities. Saúde em Debate, 37, 571-579. http://dx.doi.org/10.1590/S0103-11042013000400004

Grandi, J., Days, M. T. G., \& Glimm, S. (2013) Perceptions of Those Who Ask-What's Your Color? Rio de Janeiro, 37, 588-596.

Guimarães, A. S. A. (1999). Racism and Anti-Racism in Brazil (Ed. 34). Sao Paulo: Foundation to support the University of São Paulo.

Klein, H. S.; III, Ben Vinson (2007). African Slavery in Latin America and the Caribbean (2nd ed.). New York: Columbia University.

OHCHR and UNESCO (2001). The World Conference against Racism, Racial Discrimination, Xenophobia and Related Intolerance. Durban.

Osório, R. G. (2003). The Classification System of "Color or Race" at IBGE. Discussion Paper 996, Brasilia: IPEA.

Ribeiro, D. A. (2012). Ubuntu: Human Rights and the Health of the Black Population. In: L. E. Batista, J. Werneck, \& F. Lopes (Org.), Health of the Black Population (2nd ed., pp. 122-145). Rio de Janeiro: Brazilian Association of Black Researchers. (Black and Black Collection: Research and Debates)

Roediger, D. (2000). Towards the Abolition of Whiteness. London: Verso.

Santos, J. E., \& Santos, G. C. S. (2013). Narratives of Primary Care Professionals on the National Comprehensive Health Policy for the Black Population. Health Care Debate, 37, 571-579.

Santos, M. A. (2007). Moreninho, Neguinho, Pretinho (Little Brown, Little Negro, Little Black). Brasilia: Ministry of Education.

Silva Filho, P. (2008). Affirmative Action Policies in Brazilian Education: A Case Study of Vacancies Reserve Program for Entry into the Federal University of Bahia. Doctoral Thesis, Salvador: UFBA.

Tavares, N. O., Oliveira, L. V., \& Lages, S. R. C. (2013). The Perception of Psychologists about Institutional Racism in Public Health. Health Care Debate, 37, 571-579.

Scientific Research Publishing

\section{Submit or recommend next manuscript to SCIRP and we will provide best service for you:}

Accepting pre-submission inquiries through Email, Facebook, LinkedIn, Twitter, etc.

A wide selection of journals (inclusive of 9 subjects, more than 200 journals)

Providing 24-hour high-quality service

User-friendly online submission system

Fair and swift peer-review system

Efficient typesetting and proofreading procedure

Display of the result of downloads and visits, as well as the number of cited articles

Maximum dissemination of your research work

Submit your manuscript at: http://papersubmission.scirp.org/

Or contact aasoci@scirp.org 